\title{
Conhecimentos Evidenciados Por Futuras Professoras de Matemática Sobre os Números Racionais e Sobre seu Ensino
}

\section{Knowledge Evidenced By Future Mathematics Teachers about Rational Numbers and How to Teach Them}

\author{
Lana Thaís Santos Silva*a; Thayse de Fátima Oliveira Santos ${ }^{\mathrm{a}}$; Rafael Neves Almeida ${ }^{\mathrm{a}}$; Marta Élid Amorim
}

${ }^{a}$ Universidade Federal de Sergipe. SE, Brasil.

*E-mail: santoslana89@gmail.com

\begin{abstract}
Resumo
Este artigo objetiva identificar os conhecimentos evidenciados por um grupo de licenciandas ao ensinar noções e procedimentos concernentes ao conceito de fração e à resolução de operações em Q na Educação Básica. Considera-se as categorias refinadas por Ball, Thames e Phelps a partir de trabalhos de Shulman, no que diz respeito aos conhecimentos necessários ao professor que ensinará Matemática. Opta-se por discutir neste trabalho os resultados de dois questionários aplicados a quatro estudantes de um curso de Licenciatura em Matemática ao iniciar uma formação sobre números racionais e seu ensino, vinculada ao projeto de pesquisa "Um estudo sobre os conhecimentos necessários ao professor de matemática para ensinar frações”. As respostas das participantes a esses questionários indicaram dificuldades como: localizar frações na reta numérica; fixar uma unidade comum a todas as frações para ser o inteiro e compará-las; e representar uma fração em que o denominador seja maior que o numerador. Esses desafios, muito presentes em alunos da Educação Básica, persistem mesmo após essas licenciandas terem integralizado mais de 50\% do curso. Diante disso, considera-se que o formador de professores precisaria incluir em suas aulas situações que lhe permita discutir com os futuros professores aspectos relacionados ao conteúdo, às causas dos erros cometidos pelos alunos e maneiras de superá-las.
\end{abstract}

Palavras-chave: Formação de Professores. Ensino de Fração. Conhecimento Comum do Conteúdo. Conhecimento do Conteúdo Especializado.

\begin{abstract}
The goal of this article is to identify the knowledge that a group of student-teachers has for teaching notions and procedures regarding the concept of fractions and solving equations in Q in Basic Education. We consider the categories refined by Ball, Thames and Phelps, based on the works of Shulman, with respect to the knowledge necessary for a teacher to teach Mathematics. In this paper, we have chosen to discuss the results of two questionnaires applied to four students in a Mathematics Teaching Degree program at the start of the training program on Rational Numbers and how to teach them, linked to the research project "A study on the knowledge necessary for a Mathematics teacher to teach fractions" (Um estudo sobre os conhecimentos necessários ao professor de matemática para ensinar frações). The participants' answers to these questionnaires indicated difficulties, such as: locating fractions on a number line; finding a common unit for all fractions to be a whole number and, thus, be able to compare them; and representing a fraction in which the denominator is greater than the numerator. These challenges are frequently present among students in Basic Education and they persisted even after the student-teachers completed $50 \%$ of the program. As such, we believe that teacher trainers need to include situations in their classes to discuss with future teachers aspects related to the content, to the causes of mistakes made by students and ways to fix them.
\end{abstract}

Keywords: Teacher Trainer. Teaching Fractions. Common Content Knowledge. Specialized Content Knowledge.

\section{Introdução}

De acordo com Siegler e Lortie-Forgues (2017), frações e números decimais são uma das grandes dificuldades para crianças e adultos, o que é um grande problema, pois esse conteúdo é pré-requisito para uma matemática mais avançada e possibilita adentrar os estudos das ciências e obter sucesso profissional em algumas ocupações. Nessa mesma direção, Behr, Lesh, Post \& Silver (1983) colocam o conceito dos números racionais entre os mais complexos e importantes que o aluno encontrará no Ensino Fundamental.

Toda essa complexidade reverbera no campo do ensino. Isso se deve aos números racionais carregarem consigo toda uma nova estrutura aditiva e multiplicativa, bem como um novo contexto para o número, que deixa de ser apenas um instrumento para a contagem e passa a ser utilizado também como medida, aumentando, assim, a complexidade no ensino de aritmética.

O ensino de frações nos últimos anos tem sido discutido por vários pesquisadores (Mocrosky, Tychanowicz, Panossian, Orlovski \& Andrade, 2019; Canova, Barreto, Prado \& Campos, 2019; Campos, Magina \& Nunes, 2006; Pinheiro, 2014; Garcia Silva, Pinheiro \& Canova, 2018). Eles apontam algumas reflexões sobre a formação de professores e o ensino de fração.

Estudos realizados por Damico (2007), Nunes \& Bryant (1997), Mocrosky et al. (2019), Miola \& Lima (2020) e Garcia Silva, Pinheiro \& Canova (2018), sinalizam que tanto 
professores como grande parte do alunado têm dificuldades ao trabalhar com os números racionais. Um dos fatores que contribuem para essa situação é a forma frágil como esses números são trabalhados, pois já em sua construção é priorizada a ideia de parte-todo como uma dupla contagem das partes, isso sem aprofundar a relação dessa divisão com a conservação do inteiro. Mocrosky et al. (2019, p.10) mencionam que,

no cotidiano do professor, o estranhamento vem acompanhado de questões e muitas delas emergem do ensinar e do refletir sobre o que é e como foi ensinado. No dia a dia da sala de aula assumem-se as frações como algo comum e familiar, mas, no demorar-se pensando o trabalho realizado e seus possíveis significados, vem a estranheza.

Em relação aos estudantes da Educação Básica, Silva, Barrêto \& Amorim (2017) apontam que os alunos têm dificuldade em comparar frações. Atribuem isso, principalmente, à associação feita pelos educandos entre as propriedades específicas dos números naturais e os números racionais na representação fracionária, sem considerar a conservação do inteiro.

Silva \& Almouloud (2008) mostram que, na adição de números fracionários de mesmo denominador, normalmente, os alunos não apresentam dificuldade para a compreensão, mas isso não acontece quando os denominadores são diferentes nem nas outras operações (subtração, multiplicação e divisão). No caso da soma de frações com denominadores diferentes, a abordagem de utilizar o Mínimo Múltiplo Comum (MMC) para transformar as frações em outras equivalentes e de mesmo denominador prejudica, segundo esses autores, a compreensão da definição da operação de adição.

Em relação ao tratamento dado ao enfrentamento dessas dificuldades em cursos de formação inicial de professores de Matemática, Moreira (2004, p.94) afirma que,

do ponto de vista da preparação do futuro professor para o trabalho pedagógico de construção dos racionais positivos nas salas de aula da escola, a abordagem que se desenvolve na licenciatura pode ser, também, submetida a fortes questionamentos. Ao longo de todo o processo de formação na licenciatura, o conjunto dos números racionais é visto como um objeto extremamente simples, enquanto as pesquisas mostram que, em termos da prática docente, a sua construção pode ser considerada uma das mais complexas operações da matemática escolar.

Em virtude disso, propusemo-nos a desenvolver um projeto de pesquisa intitulado "Um estudo sobre os conhecimentos necessários ao professor de matemática para ensinar frações”, vinculado às atividades do Grupo de Estudo e Pesquisa em Educação Matemática (Gepemat). Nesta pesquisa, buscamos identificar os conhecimentos que um grupo de licenciandas evidenciam ao ensinar noções e procedimentos concernentes ao conceito de fração e à resolução de operações em Q na Educação Básica, além de discutir uma proposta de formação que favorecesse o desenvolvimento e/ou a ampliação, por parte das participantes, de conhecimentos sob o ponto de vista do conteúdo para o ensino desse tema. Vale destacar que, para este trabalho, em virtude da limitação de espaço, optamos por apresentar e analisar dois questionários aplicados ao grupo de licenciandas nos primeiros encontros do curso de formação proposto.

Com o propósito de guiar o caminho enfrentado na formação de professores para discutir o ensino de fração, faremos uma discussão sobre o conhecimento necessário para ensinar fração. Em seguida, com base nas categorias de Ball, Thames e Phelps (2008), discutiremos os conhecimentos evidenciados pelas licenciandas quando são levadas a pensar sobre o ensino dos números racionais, com foco principal no Conhecimento Comum do Conteúdo (CCK), no Conhecimento do Conteúdo Especializado (SCK) e no Conhecimento do Conteúdo e do Ensino (KCT). Por fim, apresentaremos algumas considerações acerca dos resultados obtidos.

\section{Que é Necessário Para Ensinar Fração?}

$\mathrm{Na}$ perspectiva de saber quais os conhecimentos necessários para o docente mediar suas aulas, Shulman (1986) apresenta estudos sobre a implementação de estratégias pedagógicas, levando em consideração o conteúdo específico para o professor. A partir disso, Shulman (1987) elabora alguns fundamentos que tratam de tipos de habilidades e conhecimentos necessários aos docentes ao longo de sua jornada, a fim de promover um ensino de qualidade. Com isso, estabelece uma base de conhecimentos para a docência que, no mínimo, deveria incluir: Conhecimento do Conteúdo; Conhecimento Pedagógico Geral; Conhecimento do Currículo; Conhecimento Pedagógico do Conteúdo; Conhecimento dos Alunos e da Aprendizagem; Conhecimento dos Contextos Educativos; Conhecimento dos fins educacionais e propositivos e dos valores e de seus fundamentos filosóficos e históricos.

Dentre tantas pesquisas oriundas do trabalho desenvolvido por Shulman (1986, 1987), destacamos a de Ball et al. (2008), que fazem uma releitura de Shulman aprofundando os estudos e apresentam o modelo teórico dos conhecimentos matemáticos necessários aos professores de Matemática. Nesse estudo, os autores desenvolveram e refinaram categorias definidas anteriormente por Shulman $(1986,1987)$ e subdividiram o Conhecimento do Conteúdo em Conhecimento Comum do Conteúdo, Conhecimento do Conteúdo Especializado e Conhecimento Horizontal do Conteúdo; e o Conhecimento Pedagógico do Conteúdo foi fracionado em Conhecimento do Conteúdo e dos Estudantes, Conhecimento do Conteúdo e do Ensino e Conhecimento do Conteúdo e do Currículo.

Como dito anteriormente, neste trabalho, analisaremos dados relacionados às categorias do Conhecimento Comum do Conteúdo (CCK), do Conhecimento do Conteúdo Especializado (SCK) e do Conhecimento do Conteúdo e do Ensino (KCT) de Ball et al. (2008). O Conhecimento Comum do Conteúdo refere-se à compreensão essencial da Matemática 
que todo cidadão pode ter. Não é de exclusivo domínio daqueles que lecionam. Ou seja, o Conhecimento Comum do Conteúdo é todo aquele inerente ao indivíduo, desde os cálculos básicos até os mais avançados, cotidianamente aplicados por vários profissionais de distintas áreas em suas respectivas profissões.

Temos, por exemplo, chefes de cozinha, padeiros, músicos, jornalistas, encanadores, que usam os números racionais em suas áreas para resolver situações corriqueiras, como é o caso dos encanadores, que utilizam frações para escolher o tamanho correto das instalações hidráulicas. Em receitas, é comum ter como unidade de medida os números racionais. Na música, a razão entre o comprimento das cordas e o tempo do compasso também é marcada por esses números. Em todos os exemplos citados, o profissional não necessita saber as propriedades, por que tal cálculo é feito daquela maneira, quais conceitos estão envolvidos, o importante, para eles, é sua aplicação para desenvolver sua prática. Por isso, esse conhecimento é tido como inerente ao indivíduo e classificado por Ball et al. (2008) como Conhecimento Comum do Conteúdo.

O Conhecimento do Conteúdo Especializado, diferentemente do anterior, é de atribuição exclusiva da prática docente. Trata-se daquele que possibilita ao professor explicar procedimentos matemáticos, perceber e analisar possíveis erros dos alunos, elaborar justificativas para esclarecer dúvidas. De acordo com Almeida (2015), esse conhecimento não é para ser ensinado ao aluno; entretanto, faz parte do leque de conteúdos necessários à atividade docente e exige uma forma bem específica de pensar sobre a Matemática.

No que tange ao Conhecimento do Conteúdo Especializado do professor que ensinará frações, é necessário que ele saiba, entre outras coisas, seus diferentes significados. Nunes, Bryant, Pretzlik \& Hurry (2003) nos indicam que esse conceito, quando trabalhado mediante seus cinco significados - número, relação parte-todo, medida, quociente e operador multiplicativo - , pode contribuir bastante com a compreensão sobre ele. Isso se deve a essa prática possibilitar ao aluno um leque de estratégias que lhe permitirá elaborar outras conjecturas que a noção parte-todo, a abordagem mais frequente em livros didáticos, não abrange.

O significado de parte-todo provém da ação de particionar um todo - contínuo ou discreto - em $\mathrm{n}$ partes iguais, em que cada parte representa 1/n (Moutinho, 2005). A fração resultante dessa ação é dada pelo número de partes em que foi dividido o todo representa o denominador e pelo número de partes que desejamos tomar, o numerador.

O significado de quociente está presente em situações que exploram a ideia de divisão ou partilha e nos possibilita representar frações que o conceito de divisão do todo em partes iguais não nos permitiria. Por exemplo, "dividir uma unidade em 3 partes e tomar 2 dessas partes é uma situação diferente daquela em que é preciso dividir 2 unidades em 3 partes iguais. No entanto, nos dois casos, o resultado é dado pelo mesmo número 2/3." (Brasil, 1998, p.103).
No momento em que discutimos com os alunos situações nas quais é preciso fazer comparações entre números fracionários, trabalhamos o significado de fração como número (Ministério da Educação, 1998). Outro significado de fração é aquele que envolve situações de medida. Nesse caso, utilizamos determinada parte como referência para medir as demais. E, por último, há a fração como operador multiplicativo, em que a ideia implícita é a de que o número é um multiplicador da quantidade indicada (Campos et al., 2006).

O Conhecimento do Conteúdo e do Ensino é aquele que possibilita ao professor elaborar estratégias de ensino que proporcionem a aprendizagem dos alunos, capacitem-no para avaliar vantagens e desvantagens de métodos de ensino. Essa categoria se assemelha ao Conhecimento do Conteúdo Especializado, pois é de domínio exclusivo da prática docente, mas difere dele por ser mais voltado à compreensão das diferentes abordagens, dos recursos metodológicos e das formas de trabalhar o conteúdo em sala de aula.

Tudo o que foi mencionado anteriormente são algumas características do que é necessário que o professor saiba para ensinar fração. Sendo assim, compreender os conhecimentos matemáticos para o ensino nos permite estudar aqueles evidenciados por licenciandas do Curso de Licenciatura em Matemática ao planejarem e discutirem atividades para o ensino do conceito de fração e as quatro operações fundamentais no conjunto $\mathrm{Q}$.

\section{Material e Métodos}

Este texto configura-se uma pesquisa qualitativa, utilizada, segundo Gonsalves (2011), quando há a preocupação com a compreensão e a interpretação dos fenômenos, considerando o significado que os outros dão a suas práticas. Assim, buscamos fazer uma análise qualitativa para verificar as evidências individuais de cada participante no que diz respeito aos conhecimentos para ensinar o conceito de fração e as quatro operações fundamentais no conjunto Q.

Os dados do trabalho em questão foram coletados diretamente com os sujeitos em aulas da disciplina optativa de Tópicos de Ensino de Matemática. Assim, este estudo se caracteriza como uma pesquisa de campo. Para Gonsalves (2011), em uma investigação dessa natureza, o pesquisador vai ao espaço onde o fenômeno ocorre ou ocorreu e reúne um conjunto de informações a serem analisadas.

Participaram dessa experiência, quatro discentes do Curso de Licenciatura em Matemática, da Universidade Federal de Sergipe, Campus "Prof. Alberto Carvalho". Essas alunas são ex-bolsistas do Programa Institucional de Bolsas de Iniciação à Docência (Pibid) e já possuem mais de 50\% do curso integralizado. Para a identificação dos protocolos, de modo a resguardar a identidade de cada aluna, optamos por identificálas pelos pseudônimos Jennifer, Karol, Lays e Isabella.

Esta investigação aconteceu em três etapas. Primeiramente, aplicamos os instrumentos diagnósticos. Na 
segunda, propusemos situações com a finalidade de promover discussões sobre o processo de ensino e de aprendizagem dos diferentes significados do conceito de fração e, ao mesmo tempo, investigar em que medida essas discussões podem interferir no planejamento e na elaboração de atividades voltadas para o ensino desses conceitos. Na última etapa, debatemos sobre o processo de ensino e aprendizagem das quatro operações fundamentais no conjunto $\mathrm{Q}$.

Os dados analisados neste trabalho foram dois questionários respondidos pelas licenciandas antes das discussões da segunda e da terceira etapa do desenvolvimento do projeto. Ambos tinham como objetivo identificar quais os conhecimentos que as alunas evidenciaram, sob a luz da teoria elaborada por Ball et al. (2008).

Para a construção dos questionários, elaboramos algumas questões, mas também utilizamos e adaptamos perguntas dos trabalhos de Silva e Almouloud (2008) e Magina e Campos (2008). Além disso, fizemos uso de dados do projeto de pesquisa "Aritmética no Ensino Fundamental", desenvolvido pelo Gepemat.

\section{Resultados e Discussão}

Pautamo-nos nas categorias elencadas por Ball et al. (2008) para elaborar questões que identificassem diferentes conhecimentos. Todavia, ao fazer a análise das resoluções apresentadas pelas licenciandas, procuramos identificar, para este trabalho, aquelas que se enquadraram nas categorias Conhecimento Comum do Conteúdo (CCK), Conhecimento do Conteúdo Especializado (SCK) e Conhecimento do Conteúdo e do Ensino (KCT). Quando aplicamos o instrumento que continha as questões que discutiremos aqui, tínhamos por objetivo evidenciar se as futuras professoras conseguiam identificar diferentes significados de frações e como elas, supostamente, abordariam esse conteúdo em sala de aula.

A Questão 1 envolve o significado de número. Para sua resolução, é necessário mobilizar o invariante denominado por Vergnaud de relação de ordem, uma vez que 1/4 e 1/2 operam sobre "todos" idênticos (Magina \& Campos, 2008).

Figura 1 - Questão 1 do Questionário I

Questão 1: Maria e Paulo receberam uma barra de chocolate de mesmo tamanho cada um. Maria comeu $\frac{1}{4}$ do chocolate dela e Paulo comeu $\frac{1}{2}$ do chocolate dele.

Quem comeu mais chocolate, Maria ou Paulo?
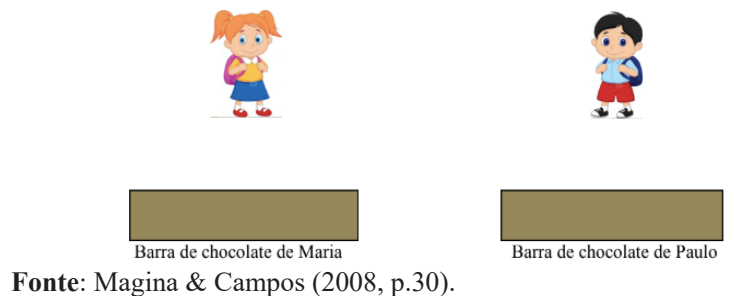

A Questão 2 contém uma situação-problema que aborda o significado de operador multiplicativo, como podemos ver na Figura 2.
Figura 2 - Questão 2 do Questionário I

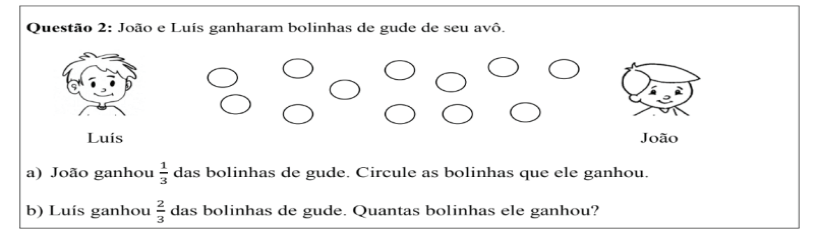

Fonte: Amorim, Etcheverria \& Oliveira (2019, p.202).

Para a identificação do total de bolinhas que as duas crianças ganharam de seu avô, é possível multiplicar 1/3 por 12 e encontrar a quantidade de bolinhas que João ganhou respondendo, assim, ao item (a). E as bolinhas que restarem indicam as que Luís ganhou - solução do item (b). Outra opção para a obtenção da quantidade de bolinhas que Luís ganhou seria realizar os cálculos de maneira análoga ao item (a).

Além da resolução das questões, solicitamos que as licenciandas respondessem a duas outras perguntas. A primeira indagava se as duas questões envolvem o mesmo significado de frações. A segunda solicitava uma explicação de como ensinariam a resolução de cada uma dessas atividades a alunos do ensino básico.

Acreditamos que questões elaboradas de maneira a vincular a resposta a uma pergunta sobre o conteúdo com as reflexões teóricas e metodológicas sobre o ensino nos propiciou a identificação de diferentes conhecimentos elencados por Ball et al. (2008). Na Figura 3, temos a resposta da licencianda Lays sobre as indagações apresentadas.

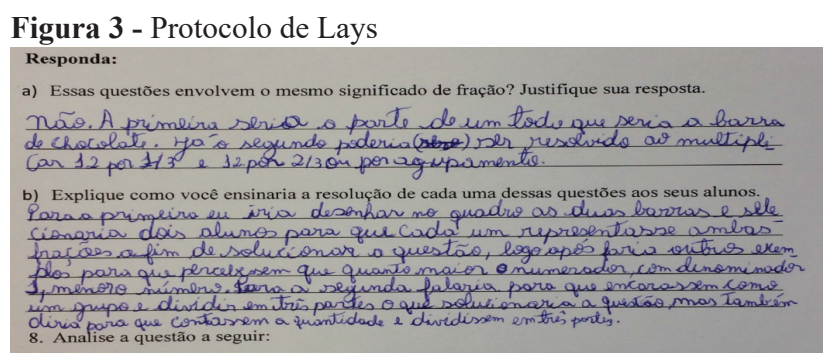

Fonte: Os autores.

No primeiro item, a licencianda apresentou uma percepção de significados diferentes de fração. Justificou uma como parte-todo e indicou que a outra questão poderia ser resolvida por operador multiplicativo ou agrupamento, sem especificar como faria o agrupamento. No entanto, quando solicitamos que descrevesse como explicaria as questões a seus alunos, optou por tratar os dois problemas como parte-todo, visto que, para a Questão 2, ela mencionou que pediria para os estudantes contarem o total de bolinhas, ou seja, o todo, para, posteriormente, dividi-lo em três partes, o que nos faz acreditar que era esse o agrupamento a que se referia no item anterior.

Como resposta para esses questionamentos, a licencianda Isabella utilizou exclusivamente ideias relacionadas ao significado de parte-todo. Ela afirmou que esse é o significado envolvido na primeira situação proposta; no entanto, não 
apresentou estratégias de comparação dos números $1 / 4$ e $1 / 2$. Para a segunda situação, também subdividiu o todo (12 unidades) em 3 partes iguais (com 4 unidades cada) e tomou uma delas no item (a) e duas no item (b), não fazendo a opção de usar o operador multiplicativo, como podemos observar na Figura 4.

\section{Figura 4 - Protocolo de Isabella}

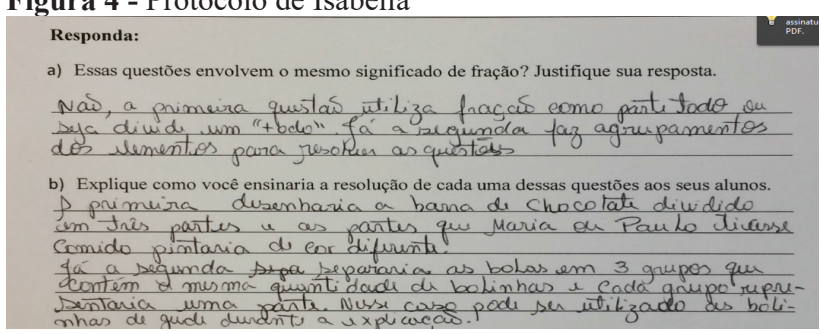

Fonte: Os autores.

Podemos observar que as licenciandas priorizaram o significado de parte-todo. No entanto, Lays introduziu outros elementos na discussão, como a possibilidade de resolver a Questão 2 multiplicando 12 por $1 / 3$ e 12 por 2/3 - significado de operador multiplicativo - e fez uma tentativa de comparar os valores do numerador e do denominador das frações. Apesar de ter feito uma confusão de nomenclaturas, parecenos que a intenção da licencianda era comparar frações de mesmo numerador - $1 / 2 \mathrm{e}^{1 / 4}$-, visto que, nesse caso, quanto maior o denominador, menor o número.

Com isso, foi evidenciado que as duas licenciandas têm compreensão do conteúdo e de estratégias de ensino que supostamente auxiliariam no processo de ensino e aprendizagem, mesmo que de forma incipiente. Em suas escritas, elas exteriorizaram o Conhecimento do Conteúdo e do Ensino ao apresentarem justificativas para suas resoluções e táticas pedagógicas.

Para a Questão 1 do Questionário II, todas as licenciandas expuseram mais de uma resolução, de maneira correta, fato exemplificado na resposta apresentada por Jennifer (Figura 5).

Figura 5 - Protocolo de Jennifer

1. Resolva a soma $\frac{3}{2}+\frac{3}{4}$ utilizando todos os métodos que você conhece. $\frac{6+3}{4}=\frac{9}{4} ; \frac{3}{2}+\frac{3}{4}=\frac{12+6}{8}=\frac{18}{8}=\frac{9}{4} ; \frac{3}{2}+\frac{3}{4}=\frac{6}{4}+\frac{3}{4}=\frac{9}{4}$

Fonte: Os autores.

Dessa forma, podemos afirmar que as licenciandas demonstraram possuir o Conhecimento Comum do Conteúdo. No entanto, como a questão não solicitava as justificativas dos procedimentos, não temos elementos para fazer afirmações sobre o Conhecimento do Conteúdo Especializado. Elas se restringiram a responder o que foi pedido e não deram uma resposta que deixasse claro, por exemplo, o "porquê" de o procedimento utilizado funcionar. Ainda assim, ao indicarem mais de uma resolução, explicitaram conhecimentos referentes ao SCK, visto que esse fato favorece a proposição de atividades e alarga os argumentos, o que fortalece, inclusive, o Conhecimento do Conteúdo e do Ensino.

Outra questão elaborada com o objetivo de identificarmos o CCK desse grupo de licenciandas foi a exposta na Figura 6.

Figura 6 - Questão 2 do Questionário II

Represente em uma reta numérica as seguintes frações $\frac{11}{8}, \frac{2}{3}, 4 \frac{1}{2}, \frac{5}{4}$ em seguida as represente geometricamente.

Fonte: Os autores.

Nessa questão, a Jennifer (Figura 7) fez uma tentativa de representação pictórica, mas cometeu erros ao ilustrar frações cujos denominadores eram maiores que os numeradores, ou seja, frações maiores que o inteiro. Essa licencianda não apresentou sequer um esboço da representação das frações na reta numérica.

Figura 7 - Protocolo de Jennifer

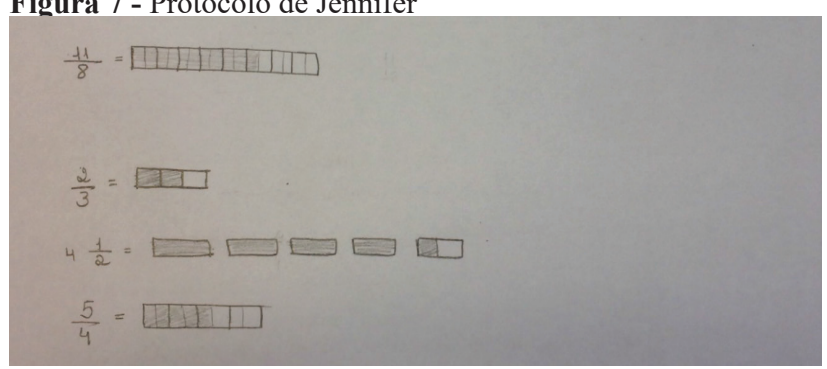

Fonte: Os autores.

A representação pictórica, por vezes, pode não permitir esboçar a resposta correta. Isso aconteceu com os participantes da pesquisa de Caseiro e Ribeiro (2012).

Dois fatos nos chamaram a atenção na resposta apresentada por Jennifer. Acreditamos que sua intenção era comparar as frações e, assim, conseguir ordená-las e representá-las na reta numérica. No entanto, cometeu o erro de não fixar uma unidade comum a todas as frações para ser o inteiro.

No contexto dos documentos oficiais no âmbito nacional, os Parâmetros Curriculares Nacionais (PCN) e a Base Nacional Comum Curricular (BNCC), de autoria do Ministério da Educação $(1997,2017)$ mencionam que o ensino de fração deve ser trabalhado com os diferentes significados. Também indicam que esse trabalho tenha início de maneira implícita no segundo ano do Ensino Fundamental, mas o termo "fração" só é de fato explicitado a partir do quarto ano do Ensino Fundamental. Na BNCC, a fração é abordada na unidade temática "Números", e espera-se que os alunos aprendam estratégias que lhes possibilitem ordenar, fazer uso de conjecturas para resolver e elaborar problemas que envolvam as operações com números racionais (Ministério da Educação, 2017). Diante disso, espera-se que o futuro professor tenha conhecimentos para resolver problemas envolvendo frações.

Entretanto, os resultados que encontramos vão ao encontro de outros artigos, como o de Silva et al. (2017), que mostram que esse movimento de não fixar uma unidade comum como o inteiro para comparar frações é um erro frequente também 
entre alunos do sexto ano do Ensino Fundamental. Na mesma direção, Silva et al. (2019, p. 11) mostram que

estudantes do curso de Matemática, têm dificuldades em: localizar frações na reta numérica, fixar uma unidade comum a todas as frações para ser o inteiro e, assim, poder comparálas e representar uma fração em que o denominador seja maior que o numerador.

Isso evidencia que alunos passam anos de sua vida escolar sem compreender conceitos básicos, o que vem a ter reflexos no Ensino Superior.

Outra situação presente nesse excerto é que, nas duas vezes que precisou representar a fração em que o denominador era menor que o numerador, a licencianda fez a opção equivocada de multiplicar o denominador por 2. Representou, dessa forma, 11/16 e 5/8, em vez de 11/8 e 5/4, como havia sido solicitado.

Era esperado que estudantes do Curso de Licenciatura em Matemática com mais da metade do curso integralizado, que já realizaram atividades de iniciação à docência, pudessem fazer ordenações e representações na reta numérica sem maiores problemas. Diferentemente disso, como podemos observar na Figura 8, Karol não conseguiu ao menos elaborar uma estratégia que pudesse ajudá-la a fazer uma aproximação para localizar os pontos na reta.

Figura 8 - Protocolo de Karol (Banco de dados dos autores). 4. Represente em uma reta numérica as seguintes frações $\frac{11}{8}, \frac{2}{3}, 4 \frac{1}{2}, \frac{5}{4}$,em seguida as represente geometricamente.

nä consigo representar uma fracáo em uma reta númerica Fonte: Os autores.

Esses fatos nos fazem perceber que até mesmo no curso superior os alunos enfrentam dificuldades ao trabalhar com os números racionais, principalmente em identificá-los na reta numérica. Essa constatação corrobora os resultados obtidos por Silva et al. (2019).

As licenciandas Lays e Isabella conseguiram resolver o problema, transformando as frações em números decimais e, posteriormente, localizando-os na reta. Contudo, esperamos que um professor que domine o conteúdo saiba várias formas de abordá-lo e distintas maneiras de resolvê-lo, o que não ocorreu, evidenciando, assim, limitações do Conhecimento do Conteúdo Especializado.

Ainda no que se refere ao Conhecimento do Conteúdo Especializado, destacamos a resolução apresentada por Karol para a questão indicada na Figura 9:

Figura 9 - Questão 5 do Questionário II

\section{1}

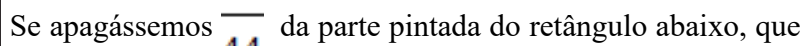
parte desse retântgtilo permaneceria pintada? Dê a sentença matemática que representa o que você fez.

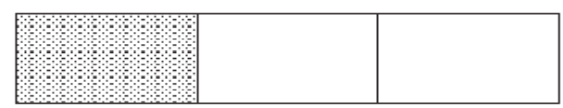

Fonte: Silva \& Almouloud (2008, p.7).
Todas as alunas resolveram corretamente essa questão, mas a resolução de Karol chamou atenção, pois demonstrou uma compreensão detalhada, diferentemente do observado na questão anterior, para a qual não foi apresentada resposta. Esse fato nos fez refletir sobre as nuances de ser ou se constituir professor, visto que um (futuro) professor pode possuir muitos conhecimentos para o ensino de um determinado conteúdo ou parte dele, ao passo que, para outros conteúdos, seus conhecimentos sejam limitados. Assim, vejamos a Figura 10, que apresenta como a licencianda procedeu.

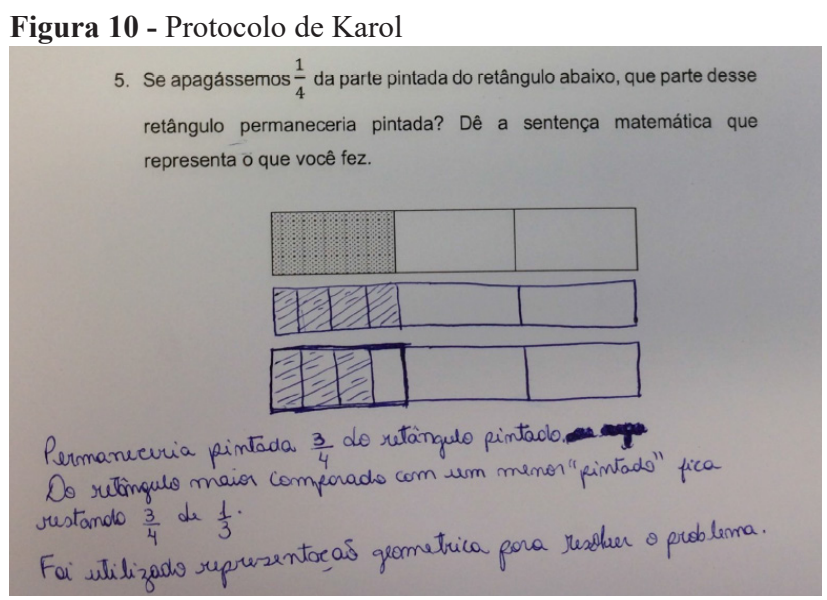

Fonte: Os autores.

Para essa questão, a licencianda demonstrou ter entendido o que foi solicitado e apresentou a resposta por meio de uma representação associada ao conceito "parte-toḑ". Embora, a resposta não fosse a esperada, que seria $3 / 12 \frac{3}{12}$, apresentou uma explicação correta para a resolução da questão, a qual evidencia uma compreensão do todo, pois, em um primeiro momento, ela tomou a parte hachurada como sendo o todo, mas, para representar a sentença matemática solicitada, Karol deu indícios de possuir conhecimento de que a parte tracejada por ela e indicada como resposta era $3 / 4 \frac{3}{4}$ de um terço do todo.

Na Figura 11, apresentamos a resposta de Isabella à questão "Escreva uma regra para a adição de duas frações quaisquer. Em seguida, explique quais recursos e metodologias você usaria para ensinar essa regra aos alunos da educação básica", adaptada de Silva e Almouloud (2008). Podemos verificar que a licencianda faz uma resolução típica da atividade docente.

Figura 11 - Protocolo de Isabella

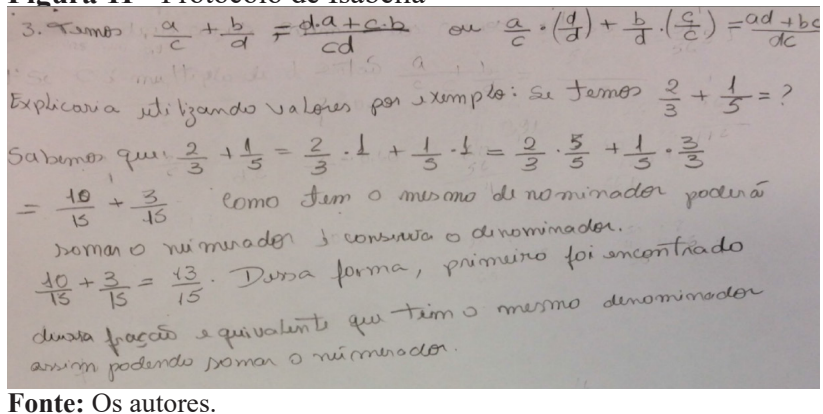

Essa resolução envolve a explicação de um procedimento 
e do "porquê" de a técnica funcionar. Tal conhecimento faz parte daquele que Ball et al. (2008) consideram como o do Conteúdo Especializado.

A questão seguinte, adaptada de Magina \& Campos (2008), foi elaborada pelos pesquisadores do projeto "Aritmética no Ensino Fundamental" e aplicada a estudantes da rede pública da Educação Básica. Seus professores também responderam à questão; e foi perguntado, adicionalmente, o percentual de discentes que a solucionariam corretamente. Esses dados foram incluídos em nosso instrumento com o objetivo de que as licenciandas fizessem uma análise sobre os motivos da discrepância entre os resultados obtidos e os indicados pelos professores.

Figura 12 - Questão do Questionário I

Analise a questão abaixo:

Cada quadro indica a quantidade de crianças e a quantidade de bolos a serem divididos entre elas.

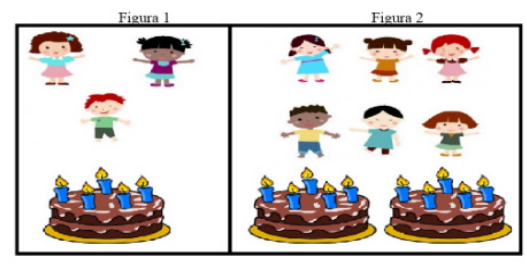

a) As 9 crianças comerão a mesma quantidade de bolo?

( ) $\operatorname{Sim}$ ( ) Não

b) Que fração representa a divisão do bolo na figura 1?

c) Que fração representa a divisão do bolo na figura 2?

Nessa questão, foi perguntando aos professores qual o percentual provável de acerto dos estudantes de sua turma de $6^{\circ}$ ano. A resposta foi que $40 \%$ dos estudantes acertariam cada item. Enquanto os estudantes acertaram 54\%, 27\% e 33\%, respectivamente. $\mathrm{O}$ que você considera como fator responsável por esses índices?

Fonte: Adaptado de Magina e Campos (2008, p. 30).

No protocolo a seguir, podemos notar que a Jennifer mencionou o conceito de fração equivalente e apontou as possíveis causas dos baixos índices. Essa tarefa de identificar prováveis causas para os erros dos alunos faz parte do Conhecimento do Conteúdo Especializado; e foi a partir dele que a licencianda conseguiu elaborar suas conjecturas, como podemos observar na Figura 13.

Figura 13 - Protocolo de Jennifer

a) Nessa questão foi perguntando ao professor qual percentual provável de acerto dos estudantes de sua turma de $6^{\circ}$ ano. A resposta foi que $40 \%$ dos estudantes acertariam cada item. Enquanto que os estudantes acertaram $54 \%, 27 \%$ e $33 \%$, respectivamente. O que voce considera como fator responsável por esses índices?

sue os alunos naie estä́s sabendo as fracöes equevalent e que eles pederm naie ter percibido no item (C). E no item (b) eles podern máo ter compreendido que o bolocomo sench o tedo seria dinidido para as três criancepas.

Fonte: Dados da pesquisa.

Diferentemente da resposta apresentada por Jenniffer, Isabella fez uma tentativa de relacionar os diferentes índices de acertos indicados pelas professoras aos distintos significados do conceito de fração. Não se dando conta de que os itens envolvem o mesmo significado, precisando apenas que se perceba que as frações são equivalentes. Talvez, Isabella não tenha conseguido notar essa equivalência, pois respondeu erroneamente que a fração que representa a divisão do bolo na Figura 2 era 1/6.

Figura 14 - Protocolo de Isabella

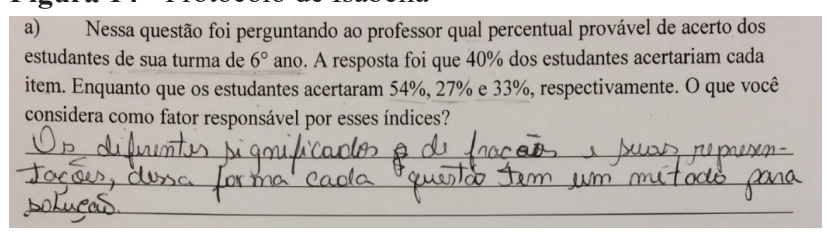

Fonte: Dados da pesquisa.

Podemos concluir que as dificuldades presentes no ensino de fração não são de exclusividade do ensino básico. Compreendemos que trabalhar com tal conceito não é uma tarefa fácil, pois há alguns fragmentos na formação que acabam contribuindo para um ciclo vicioso em torno das dificuldades presentes no processo de ensino e de aprendizagem. Essa mesma conclusão foi apresentada por Miola \& Lima (2020), que, ao analisarem os conhecimentos de professores de Matemática e Pedagogia, percebem uma lacuna no tocante aos conhecimentos matemáticos para o ensino.

\section{Conclusão}

No trabalho desenvolvido, buscamos discutir os conhecimentos necessários para a prática docente, mesmo aqueles que não são de exclusivo domínio de quem leciona. Para isso, analisamos questionários com perguntas específicas sobre números racionais. Os resultados mostram que, mesmo estudantes do curso de Matemática, têm dificuldades em: localizar frações na reta numérica; fixar uma unidade comum a todas as frações para ser o inteiro e, assim, poder comparálas; e representar frações em que o numerador seja maior que o denominador.

Essas evidências nos levam a concluir que as licenciandas apresentaram limitações no Conhecimento Comum do Conteúdo e, consequentemente, no Conhecimento do Conteúdo Especializado, no tocante aos números racionais. Isso nos remete a Damico (2007), que constata que os cursos de formação de professores de Matemática não têm conseguido produzir com seus alunos um conhecimento sobre números racionais adequado à profissão.

Outro aspecto que constatamos é que as futuras professoras, participantes da pesquisa, não conseguiram discutir de maneira ampla as causas dos erros cometidos pelos alunos ou dos baixos índices de rendimento. Pensando nisso, é importante destacar que o formador de professores precisaria incluir em suas aulas situações que levem ao debate não só do conteúdo, mas também das causas dos erros cometidos pelos alunos e das maneiras de superá-las, com vistas a promover o Conhecimento do Conteúdo e do Ensino do futuro professor. Esse seria um caminho para que estudantes em formação inicial pudessem, além de sanar suas próprias dificuldades em relação ao conteúdo, elaborar atividades diferenciadas, que incluam a compreensão dos conceitos e a busca de 
justificativas matematicamente válidas.

\section{Referências}

Almeida, R. N. (2015). Professores de Matemática em início de carreira: contribuições do Pibid (Tese de Doutorado, Universidade Anhanguera de São Paulo).

Amorim, M.E., Etcheverria, T.C., \& Oliveira, M.R. (2019). Fração com o significado de operador multiplicativo: aprendizagem e ensino. JIEEM, 12(2), 199-206. doi: 10.17921/2176-5634.2019v12n2p199-206.

Ball, D.L., Thames, M.H., \& Phelps, G. (2008). Content knowledge for teaching what makes it special? J. Teacher Educ., 59(5), 389-407. doi: 10.1177/0022487108324554.

Behr, M., Lesh, R., Post, T., \& Silver, E. (1983). Rational Number Concepts. In R. Lesh \& M. Landau (Eds.), Acquisition Mathem. Concepts and Processes (pp. 91-125). New York: Academic Press.

Brasil. Ministério da Educação (1998). Parâmetros Curriculares Nacionais: Matemática. Brasília: SEF/MEC.

Brasil. Ministério da Educação (2017). Base Nacional Curricular Comum: educação é a base. Brasília: SEB/MEC.

Brasil. Ministério da Educação (1997). Parâmetros Curriculares Nacionais: Matemática. Brasília: SEF/MEC.

Campos, T.M M., Magina, S., \& Nunes, T. (2006). O professor polivalente e a fração: conceitos e estratégias de ensino. Educ. Matem. Pesq., 8(11), 125-136.

Caseiro, A., \& Ribeiro, C. (2012) Conhecimento de futuros professores dos Primeiros Anos: uma experiência com racionais. In R. Cadima, I. Pereira, H. Menino, I. S. Dias \& H. Pinto (Eds.), Conferência Internacional de Investigação, Práticas e Contextos em Educação (pp. 393-400). Leiria: Escola Superior de Educação e Ciências Sociais, Instituto Politécnico de Leiria.

Canova, R. F., Barreto, M. G. B., Prado, M. E. B. B., \& Campos, T. M. M. (2019). Formação continuada: uma parceria para refletir sobre o ensino de fração. Revisem, 1, 110-122. doi: 10.34179/revisem.v4i1.10049.

Damico, A. (2007). Uma investigação sobre a formação inicial de professores de matemática para o ensino de números racionais no ensino fundamental (Tese de Doutorado, Pontifícia Universidade Católica de São Paulo).

Garcia Silva, A.F.; Pinheiro, M.G.C.; Canova, R.F. 2018). Análise das reflexões de uma professora dos anos iniciais participante do Observatório da Educação a Respeito da sua Prática. Bolema, 32 (62), 1113-33. doi: 10.1590/1980-4415v32n62al8

Gonsalves, E. P. (2011). Conversas Sobre Iniciação à Pesquisa
Cientifica. Campinas: Alínea.

Magina, S., \& Campos, T. (2008). A fração nas perspectivas do professor e do aluno dos dois primeiros Ciclos do Ensino Fundamental. Bolema, 21(31), 23-40.

Miola, A. F. S., \& Lima, T. E. A. (2020). Conhecimentos necessários para o ensino de números racionais no Ensino Fundamental. Educação Matemática Debate, 4(10), 1-16. doi: 10.46551/emd.e202044.

Mocrosky, L. F., Tychanowicz, S. D., Panossian, M. L., Orlovski, N., \& Andrade, S. P. (2019). Frações na formação continuada de professores dos anos iniciais: fragmentos de uma complexidade. Bolema, 33(65). doi: 10.1590/1980-4415v33n65a22.

Moreira, P. C. (2004). O conhecimento matemático do professor: formação na licenciatura e prática docente na escola básica (Tese de Doutorado, Universidade Federal de Minas Gerais).

Moutinho, L. V. (2005). Fração e seus diferentes significados: um estudo com alunos das $4^{a}$ e $8^{a}$ séries do Ensino Fundamental. São Paulo: Pontifícia Universidade Católica de São Paulo.

Nunes, T., \& Bryant, P. (1997). Crianças fazendo Matemática. Porto Alegre: Artes Médicas.

Nunes, T., Bryant, P., Pretzlik, U., \& Hurry, J. (2003). The effect of situations on children's understanding of fractions (Unpublished $\mathrm{PhD}$ Thesis). Oxford: Oxford Brookes University.

Pinheiro, M.G.C. (2014). Formação de professores dos anos iniciais: conhecimento profissional docente ao explorar a introdução do conceito de fração (Dissertação de Mestrado, Universidade Anhanguera de São Paulo).

Siegler, R. S., \& Lortie-Forgues, H. (2017). Hard Lessons: Why Rational Number Arithmetic Is So Difficult for So Many People. Current Directions in Psychological Science, 26(4), 346-351. doi: 10.1177/0963721417700129.

Silva, L. T. S., Barrêto, D. M., \& Amorim, M. E. (2017). O uso do frac-soma no ensino de frações como ferramenta de aprendizagem. Educon, 11(1), 1-9.

Silva, M. J. F., \& Almouloud, S. (2008). As operações com números racionais e seus significados a partir da concepção parte-todo. Bolema, 21(31), 55-78.

Shulman, L. S. (1986). Those who understand: knowledge growth in teaching. Educational Researcher, 15, 4-14. doi: 10.3102/0013189X015002004.

Shulman, L. S. (1987). Knowledge and teaching: foundations of the new reform. Harvard Educational Review, 57(1), 1-22. doi: 10.17763/haer.57.1.j463w79r56455411. 